\title{
Implementation of Preference Selection Index Method In Determination of People's Business Credit Receiver
}

\author{
Lince Tomoria Sianturi ${ }^{1}$, M Mesran $^{1}$, Elvitrianim Purba $^{2}$, Robbi Rahim ${ }^{3}$ \\ \{ lince.tomorias@gmail.com\} \\ ${ }^{1}$ Department Of Computer Science, STMIK Budi Darma, North Sumatera, Indonesia \\ ${ }^{2}$ Department Of Computer Science, AMIK STIEKOM Sumatera Utara, North Sumatera, Indonesia \\ ${ }^{3}$ School of Computer and Communication Engineering, Universiti Malaysia Perlis, Perlis, Malaysia
}

\begin{abstract}
Decision support system is an information system that helps decision makers in solving unstructured problems. Implementation of method methods in problem solving will make the results provided by decision support systems more effective and accurate. In this study researchers discussed the implementation of Preference Selection Index in producing business actors who will get the People's Business Credit fund. The application of the PSI method in this case helps decision makers without having to give weight to any criteria on which consideration is given to produce a decision.
\end{abstract}

Keywords: Preference Selection Index, DSS, People's Business Credit Receiver

\section{Introduction}

Credit is one of the financing provided by banks to customers who need funding in running the business. Different types of loans in a bank, from mortgages, motor vehicle loans, credit cards, or people's business loans. Of the many types of credit, which is currently in demand by the middle to lower credits in the financing of a business, known as the People's Business Credit. KUR is one of many government programs that has been started since November 2007. In the implementation of the government in cooperation with several Implementing Banks that distribute such credit, such as Bank BRI, Bank Bukopin, Bank BNI and Bank Syariah Mandiri. KUR is given by the government to micro, small, medium and cooperative business actors or known as UMKMK.

Distribution of KUR to business actors can be done either directly or indirectly, but currently more emphasized on the channeling indirectly. In this type of distribution, micro enterprises propose KUR to microfinance institutions and cooperatives in collaboration with implementing banks. The number of business actors applying for KUR to a Bank, resulting in the slow process by the bank to decide who the micro business actors who get the financing.

To handle these problems, decision makers use computer-based information systems [1] capable of producing output in the form of decisions. This system is known as the decision support system[2]-[7] Although the system is capable of producing a decision, in the application of decision makers in this case management or managers may not necessarily use these results directly. In order for the results provided by the decision support system to be more effective, the alternative calculation process uses methods, such as VIKOR[8], ELECTRE, PROMETHEE, SAW[4], MOORA, PSI[9][10]. 
Implementation of decision support system[2] helps in solving many problems such as selection of production cycle [11], determination of laser cutting process condition [9]. Heri Nurdiyanto in 2016 has also conducted research for priority development of small and medium industries in Central Lampung by using AHP. From these results helped the Department of Industry and Trade of Central Lampung to do the selection of companies that get development assistance from the local government [12].

In this study, researchers used Preference Selection Index (PSI) method to determine the feasibility of giving KUR to micro business actors. PSI method in the calculation process does not require weight, this is because the weight can be raised when the calculation process takes place. This distinguishes the PSI method from different methods compared to other SPK methods. Khorshidi and Hassani in 2014 have compared [13] the method of Preference Selection Index (PSI) with technique method for order preference by similarity to ideal solution (TOPSIS), the results of the study found that the calculation resulted by TOPSIS method resembles the calculation result with PSI method [14].

\section{Theory}

\subsection{People's Business Credit}

KUR is a financing program provided by the government of the Republic of Indonesia in collaboration with banks for Business, Micro, Small, Medium, and Cooperative (MSME) entrepreneurs who have feasibility, good business prospects, potential and ability to repay loans granted to the government. KUR has been provided by the government since 2007 and to date, many business actors are using the credit financing service.

The government has created a program of empowerment of business, micro, small, medium, and cooperatives, namely increasing access to financing sources in banks, development of entrepreneurship from business actors, increasing market of UMKMK products, reforming UMKMK regulations.

\subsection{Decission Support System}

Decision Support System is an information system that helps management in generating a decision with the help of computers [15]. The results of such a decision as though by using methods that are able to compare between one alternative with other alternatives [16].

In decision support systems applied methods in decision makers, it is intended that the results provided in decision support systems become more effective and accurate. Among the methods included in the multicriteria category are Elimination and Choice expressing Reality (ELECTRE), Technique for Order Preference by Similarity to Ideal Solution (TOPSIS)[6], Analytic Hierarchy Process (AHP), Simple Addictive Weighting SAW), Vlse Kriterijumska Optimizacija I Kompromisno Resenje (VIKOR)[17], Preference Selection Index (PSI) [9].

\subsection{Preference Selection Index (PSI) Method}

The Preference Selection Index (PSI) method was developed by Maniya and Bhatt in 2010. The PSI method is used for problem-solving related to multi-criteria in decision making (MCDM) [18]. The advantages in using this method, namely decision makers do not need to 
define the weight of each criterion used. This is because the weight used for computation has been taken or made from the calculation of Preference Selection Index method.

This method is useful when there is a conflict in determining the relative importance of attributes. In the PSI method, the results are obtained with minimal and simple calculations as they are based on statistical concepts without attribute weighting[19].

The steps in the calculation of Preference Selection Index method[11], as follows:

1. Identify goals

In the early stages, all possible alternatives, as well as the selection and size attributes for the given application must be identified.

2. Create a decission matrix

Assume that there is an alternative $\mathrm{Ai}(\mathrm{i}=1,2 \ldots, \mathrm{m})$ to be evaluated against the selection $n$ attribute $\mathrm{Cj}(\mathrm{j}=1,2 \ldots, \mathrm{n})$. Decision matrix $\mathrm{D}=\mathrm{xij}, \mathrm{i}=1,2 \ldots, \mathrm{M} ; \mathrm{J}=1,2 \ldots, \mathrm{N}$ as shown below shows the utility rank of alternative $\mathrm{Ai}$ with respect to the $\mathrm{Cj}$ selection attribute.

$$
\mathrm{Xij}=\left[\begin{array}{cccc}
x 11 & x 12 & \ldots & x 1 n \\
r 21 & r 22 & \ldots & x 2 n \\
\vdots & & & \\
x m 1 & x m 2 & \ldots & x m n
\end{array}\right]
$$

\section{Perform Normalization of Rij}

The normalized decision matrix is constructed using equations (2) and (3). If the expectation is greater is better (eg gain), then the performance of the original attribute can be normalized as follows:

$R_{i j}=\frac{x_{i j}}{x j^{\max }}$.

If the smaller the criterion the better, then the cost is categorized, then for the cost criteria as follows.

$R_{i j}=\frac{x j^{\min }}{x_{i j}}$

4. Determination of the mean value of the normalized matrix

$N=\frac{1}{N} \sum_{i=1}^{m} R_{i j}$

5. Calculates the value of preference variation

The value of preference variation $\left(\varnothing_{\mathrm{j}}\right)$ or each attribute is determined using the following equation:

$\emptyset_{j=\sum_{i=1}^{m}\left[R_{i j-N}\right]^{2}}$

6. Determine the deviation of preference value

$\Omega_{j}=1-\emptyset_{j}$

7. Determine the criteria weight

$w_{j}=\frac{\Omega_{j}}{\sum_{j=1}^{n} \Omega_{j}}$. 
8. Determination the preference selection index

$\Theta_{j}=\sum_{j=1}^{m}\left(R_{i j} W_{j}\right)$

The alternative that has the largest preference selection index is the best alternative.

\section{Result \& Discussion}

In the process of an implementing bank in selecting the eligibility of the people's business credit receivers apply the criteria specific criteria, such as Credit Status, Business Productivity, Business Condition, Guarantee Value, Long Standing. Credit status is a cost criterion, which informs whether the borrower is not receiving credit from any bank, the smaller the credit value owned by a proposer the more likely the proposer can pay the mortgage credit for the people. Business productivity is a benefit criterion that maps the business location, type of business and income/turnover owned by the prospective lender. The higher the productivity level of the proposer, the better the value. A business condition is a benefit criterion assessed from the side of resources owned by the proposer. This criterion is incorporated from human resources, management, equipment, and equipment. KUR on submission requires a guarantee. The value of the guarantee is a benefit criterion, which must be owned by the proposer. The value of this guarantee can be from home, shophouses, and land are calculated from its value. Long-standing, is a benefit criterion where the longer the business stands then the better. From the explanation can be seen the required criteria as follows:

Table 1: The Criteria and Type of Criteria

\begin{tabular}{cll}
\hline Criteria & \multicolumn{1}{c}{ Information } & Type \\
\hline $\mathrm{C}_{1}$ & Credit Status (Million) & Cost \\
$\mathrm{C}_{2}$ & Business Productivity (Million/month) & Benefit \\
$\mathrm{C}_{3}$ & Business Conditions & Benefit \\
$\mathrm{C}_{4}$ & The Value of Collateral (Million) & Benefit \\
$\mathrm{C}_{5}$ & Long Standing (Year) & Benefit \\
\hline
\end{tabular}

Table 2: Weighting of Business Contions $\left(\mathrm{C}_{3}\right)$

\begin{tabular}{lc}
\hline Information & Value \\
\hline Very Good & 4 \\
Good & 3 \\
Enough & 2 \\
Less & 1 \\
\hline
\end{tabular}

The alternatives used in the calculations consist of five (5) alternatives, namely King Burger $\left(A_{1}\right)$, Krispy Mushroom $\left(A_{2}\right)$, Family Meatballs $\left(A_{3}\right)$, Sate Ajo $\left(A_{4}\right)$, and Bakso Amat $\left(\mathrm{A}_{5}\right)$. After the criteria are determined, then in table 3 below is a list of alternatives and values of each of each criterion. 
Table 3: The Alternatives

\begin{tabular}{ccclcl}
\hline Alternative & $\mathrm{C}_{1}$ & $\mathrm{C}_{2}$ & \multicolumn{1}{c}{$\mathrm{C}_{3}$} & $\mathrm{C}_{4}$ & $\mathrm{C}_{5}$ \\
\hline $\mathrm{A}_{1}$ & 25 & 10 & Very Good & 55 & 4 \\
$\mathrm{~A}_{2}$ & 17,5 & 7,5 & Very Good & 93 & 3 \\
$\mathrm{~A}_{3}$ & 40 & 13,2 & Good & 65 & 5 \\
$\mathrm{~A}_{4}$ & 10 & 9,3 & Good & 70 & 3 \\
$\mathrm{~A}_{5}$ & 19,5 & 11 & Enough & 80 & 2 \\
\hline
\end{tabular}

Based on table 2 of the weighting of business conditions as well as alternative table, then obtained table 4 which is a table of matching rating between alternatives and criteria.

Table 4: Rating of alternative matches and criteria

\begin{tabular}{cccccc}
\hline Alternative & $\mathrm{C}_{1}$ & $\mathrm{C}_{2}$ & $\mathrm{C}_{3}$ & $\mathrm{C}_{4}$ & $\mathrm{C}_{5}$ \\
\hline $\mathrm{A}_{1}$ & 25 & 10 & 4 & 55 & 4 \\
$\mathrm{~A}_{2}$ & 17,5 & 7,5 & 4 & 93 & 3 \\
$\mathrm{~A}_{3}$ & 40 & 13,2 & 3 & 65 & 5 \\
$\mathrm{~A}_{4}$ & 10 & 9,3 & 3 & 70 & 3 \\
$\mathrm{~A}_{5}$ & 19,5 & 11 & 2 & 80 & 2 \\
\hline
\end{tabular}

In the settlement using the Preference Selection Index, after defining the goal to be achieved, the next step defines the $\mathrm{x}_{\mathrm{ij}}$ decision matrix. Below is a $\mathrm{x}_{\mathrm{ij}}$ matrix.

$$
X i j=\left[\begin{array}{lllll}
25 & 10 & 4 & 55 & 4 \\
17,5 & 7,5 & 4 & 93 & 3 \\
40 & 13,2 & 3 & 65 & 5 \\
10 & 9,3 & 3 & 70 & 3 \\
19,5 & 11 & 2 & 80 & 2
\end{array}\right]
$$

Then the next step uses equations 2 and 3 , normalizing the $\mathrm{x}_{\mathrm{ij}}$ decision matrix. For $\mathrm{C}_{1}$ because of criterion with Cost type then used equation to 3 , while for $C_{2}, C_{3}, C_{4}, C_{5}$ used equation to 2 .

$$
\begin{aligned}
& X_{j 1}^{\min }=[25 ; 17,5 ; 40 ; 10 ; 19,5] \\
& X_{j 1}^{\min }=10 \\
& R_{11}=\frac{X_{j 1}^{\max }}{X_{11}}=\frac{10}{25}=0,40 \\
& R_{21}=\frac{X_{j 1}^{\max }}{X_{21}}=\frac{10}{17,5}=0,57 \\
& R_{31}=\frac{X_{j 1}{ }_{\text {max }}}{X_{31}}=\frac{10}{40}=0,25 \\
& R_{41}=\frac{X_{j 1} \text { max }}{X_{41}}=\frac{10}{10}=1,00 \\
& R_{51}=\frac{X_{j 1}{ }_{\max }}{X_{51}}=\frac{10}{19,5}=0,51
\end{aligned}
$$




$$
\begin{aligned}
& X_{j 2}{ }^{\max }=[10 ; 7,5 ; 13,2 ; 9,3 ; 11] \\
& X_{j 2}{ }^{\max }=13,2 \\
& R_{12}=\frac{X_{12}}{X_{j 2} \max }=\frac{10}{13,2}=0,76 \\
& R_{22}=\frac{X_{22}}{X_{j 2} \max }=\frac{7,5}{13,2}=0,57 \\
& R_{32}=\frac{X_{32}}{X_{j 2}{ }^{m a x}}=\frac{13,2}{13,2}=1,00 \\
& R_{42}=\frac{X_{42}}{X_{j 2} \max }=\frac{9,3}{13,2}=0,70 \\
& R_{52}=\frac{X_{52}}{X_{j 2}{ }_{\max }}=\frac{11}{13,2}=0.83 \\
& X_{j 3}{ }^{\max }=[4 ; 4 ; 3 ; 3 ; 2] \\
& X_{j 3}{ }^{\max }=4 \\
& R_{13}=\frac{X_{13}}{X_{j 3}{ }^{m a x}}=\frac{4}{4}=1,00 \\
& R_{23}=\frac{X_{23}}{X_{j 3}{ }^{\max }}=\frac{4}{4}=1,00 \\
& R_{33}=\frac{X_{33}}{X_{j 3} \max }=\frac{3}{4}=0,75 \\
& R_{43}=\frac{X_{43}}{X_{j 3} \max }=\frac{3}{4}=0,75 \\
& R_{53}=\frac{X_{53}}{X_{j 3} \max }=\frac{2}{4}=0,75 \\
& X_{j 4}{ }^{\max }=[55 ; 93 ; 65 ; 70 ; 80] \\
& X_{j 4}{ }^{\max }=93 \\
& R_{14}=\frac{X_{14}}{X_{j 4}{ }_{\text {max }}}=\frac{55}{93}=0,59 \\
& R_{24}=\frac{X_{24}}{X_{j 4}{ }^{m a x}}=\frac{93}{93}=1,00 \\
& R_{34}=\frac{X_{34}}{X_{j 4}{ }^{\max }}=\frac{65}{93}=0,70 \\
& R_{44}=\frac{X_{44}}{X_{j 4}{ }_{\text {max }}}=\frac{70}{93}=0,75 \\
& R_{54}=\frac{X_{54}}{X_{j 4}{ }^{\text {max }}}=\frac{80}{93}=0,86
\end{aligned}
$$




$$
\begin{aligned}
& X_{j 5}{ }^{\max }=[4 ; 3 ; 5 ; 3 ; 2] \\
& X_{j 5}{ }^{\max }=5 \\
& R_{15}=\frac{X_{15}}{X_{j 5}{ }^{\max }}=\frac{4}{5}=0,80 \\
& R_{25}=\frac{X_{25}}{X_{j 5}{ }^{\max }}=\frac{3}{5}=0,60 \\
& R_{35}=\frac{X_{35}}{X_{j 5}{ }^{\max }}=\frac{5}{5}=1,00 \\
& R_{45}=\frac{X_{45}}{X_{j 5}{ }^{\max }}=\frac{3}{5}=0,60 \\
& R_{55}=\frac{X_{55}}{X_{j 5}{ }^{\max }}=\frac{2}{5}=0,40
\end{aligned}
$$

Then will get a matrix that has been normalized, the matrix $\mathrm{R}_{\mathrm{ij}}$ as follows.

$$
R i j=\left[\begin{array}{lllll}
0,40 & 0,76 & 1,00 & 0,59 & 0,80 \\
0,57 & 0,57 & 1,00 & 1,00 & 0,60 \\
0,25 & 1,00 & 0,75 & 0,70 & 1,00 \\
1,00 & 0,70 & 0,75 & 0,75 & 0,60 \\
0,51 & 0,83 & 0,50 & 0,86 & 0,40
\end{array}\right]
$$

The next step calculates the mean value of each alternative in a normalized matrix using equation 4 .

$\mathrm{N}=\frac{1}{5}(0,40+0,57+0,2+1+0,51)=0.5468$

$\mathrm{N}=\frac{1}{5}(0,76+0,57+1+0,70+0,83)=0.7727$

$\mathrm{N}=\frac{1}{5}(1+1+0,75+0,75+0,50)=0.8000$

$\mathrm{N}=\frac{1}{5}(0,59+1+0,70+0,75+0,86)=0.7806$

$\mathrm{N}=\frac{1}{5}(0,80+0,60+1+0,60+0,40)=0.6800$

Next step, use an equation to 5 to find the variation of preference.

$$
\begin{aligned}
& \emptyset_{j 11}=[0.40-0.5468]^{2}=0.0216 \\
& \emptyset_{j 21}=[0.57-0.5468]^{2}=0.0006 \\
& \emptyset_{j 31}=[0.25-0.5468]^{2}=0.0881 \\
& \emptyset_{j 41}=[1.00-0.5468]^{2}=0.2053 \\
& \emptyset_{j 51}=[0.51-0.5468]^{2}=0.0012 \\
& \emptyset_{j 12}=[0.76-0.7727]^{2}=0.0002 \\
& \emptyset_{j 22}=[0.57-0.7727]^{2}=0.0418 \\
& \emptyset_{j 32}=[1.00-0.7727]^{2}=0.0517 \\
& \emptyset_{j 42}=[0.70-0.7727]^{2}=0.0046 \\
& \emptyset_{j 52}=[0.83-0.7727]^{2}=0.0037
\end{aligned}
$$




$$
\begin{aligned}
& \emptyset_{j 13}=[1.00-0.8000]^{2}=0.0400 \\
& \emptyset_{j 23}=[1.00-0.8000]^{2}=0.0400 \\
& \emptyset_{j 33}=[0.75-0.8000]^{2}=0.0025 \\
& \emptyset_{j 43}=[0.75-0.8000]^{2}=0.0025 \\
& \emptyset_{j 53}=[0.50-0.8000]^{2}=0.0900 \\
& \emptyset_{j 14}=[0.59-0.7806]^{2}=0.0358 \\
& \emptyset_{j 24}=[1.00-0.7806]^{2}=0.0481 \\
& \emptyset_{j 34}=[0.70-0.7806]^{2}=0.0067 \\
& \emptyset_{j 44}=[0.75-0.7806]^{2}=0.0008 \\
& \emptyset_{j 54}=[0.86-0.7806]^{2}=0.0063 \\
& \emptyset_{j 15}=[0.80-0.6800]^{2}=0.0144 \\
& \emptyset_{j 25}=[0.60-0.6800]^{2}=0.0064 \\
& \emptyset_{j 35}=[1.00-0.6800]^{2}=0.1024 \\
& \emptyset_{j 45}=[0.60-0.6800]^{2}=0.0064 \\
& \emptyset_{j 55}=[0.40-0.6800]^{2}=0.0784
\end{aligned}
$$

The result of the above calculation, we get the variation of preference variation, as follows:

$$
\varphi_{\mathrm{ij}}=\left[\begin{array}{lllll}
0,0216 & 0,0002 & 0,0400 & 0,0358 & 0,0144 \\
0,0006 & 0,0418 & 0,0400 & 0,0481 & 0,0064 \\
0,0881 & 0,0517 & 0,0025 & 0,0067 & 0,1024 \\
0,2053 & 0,0046 & 0,0025 & 0,0008 & 0,0064 \\
0,0012 & 0,0037 & 0,0900 & 0,0063 & 0,0784
\end{array}\right]
$$

Then summing the rank results to the matrix $\emptyset_{i j}$

$$
\begin{aligned}
& \emptyset_{j 1}=0,0216+0,0006+0,0881+0,2053+0,0012 \\
& =0,3168 \\
& \emptyset_{j 2}=0,0002+0,0418+0,0517+0,0046+0,0037 \\
& =0,1020 \\
& \emptyset_{j 3}=0,0400+0,0400+0,0025+0,0025+0,0900 \\
& =0,1750 \\
& \emptyset_{j 4}=0,0358+0,0481+0,0067+0,0008+0,0063 \\
& =0,0977 \\
& \emptyset_{j 5}=0,0144+0,0064+0,1024+0,0064+0,0784 \\
& =0,2080 \\
& \emptyset_{j}=\left[\begin{array}{lllll}
0,3168 & 0,1020 & 0,1750 & 0,0977 & 0,2080
\end{array}\right]
\end{aligned}
$$

The next step calculates the deviation from the preference value using equation 6 $\emptyset_{j}=\left[\begin{array}{lllll}0,3168 & 0,1020 & 0,1750 & 0,0977 & 0,2080\end{array}\right]$ 
$\Omega_{j 1}=1-0,3168=0,6832$

$\Omega_{j 2}=1-0,1020=0,8980$

$\Omega_{j 3}=1-0,1750=0,8250$

$\Omega_{j 4}=1-0,0977=0,9023$

$\Omega_{j 5}=1-0,2080=0,7920$

After calculating the deviation, then calculate the weights of each criterion column using equation 7.

$\sum \Omega_{j}=0,6832+0,8980+0,8250+0,9023+0,7920$

$=4,1004$

$w_{1}=\frac{0,6832}{4,1004}=0,1666$

$w_{2}=\frac{0,8980}{4,1004}=0,2190$

$w_{3}=\frac{0,8250}{4,1004}=0,2012$

$w_{4}=\frac{0,9023}{4,1004}=0,2200$

$w_{5}=\frac{0,7920}{4,1004}=0,1931$

Then we get the weight of each criterion as follows.

$w=\left[\begin{array}{lllll}0,1666 & 0.2190 & 0,2012 & 0,2200 & 0,1931\end{array}\right]$

After the weight is obtained, the last step calculates the preference selection index using equation 8 .

$\Theta_{11}=0,40 \times 0,1666=0,06665$

$\Theta_{21}=0,57 \times 0,1666=0,09521$

$\Theta_{31}=0,25 \times 0,1666=0,04165$

$\Theta_{41}=1,00 \times 0,1666=0,16662$

$\Theta_{51}=0,51 \times 0,1666=0,08545$

$\Theta_{12}=0,76 \times 0,2190=0,16590$

$\Theta_{22}=0,57 \times 0,2190=0,12443$

$\Theta_{32}=1,00 \times 0,2190=0,21899$

$\Theta_{42}=0,70 \times 0,2190=0,15429$

$\Theta_{52}=0,83 \times 0,2190=0,18249$

$\Theta_{13}=1,00 \times 0,2012=0,20120$

$\Theta_{23}=1,00 \times 0,2012=0,20120$

$\Theta_{33}=0,75 \times 0,2012=0,15090$

$\Theta_{43}=0,75 \times 0,2012=0,15090$

$\Theta_{53}=0,50 \times 0,2012=0,10060$ 


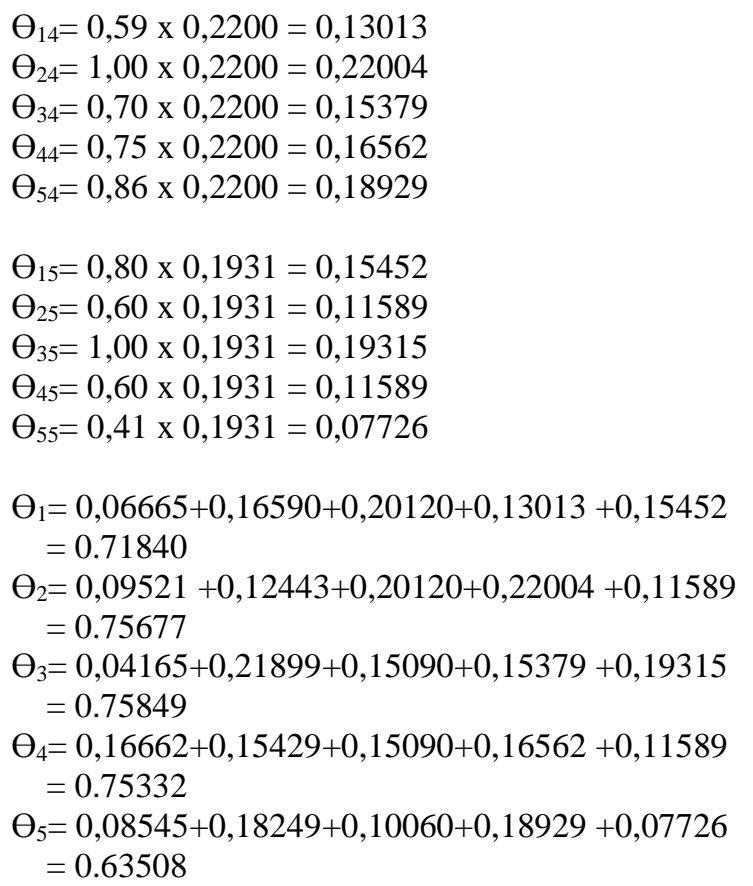

The final result of the calculation can be seen in table 5 .

Table 5: The Result of PSI

\begin{tabular}{ccc}
\hline Alternative & Value of PSI & Rank \\
\hline $\mathrm{A}_{1}$ & 0,71840 & 4 \\
$\mathrm{~A}_{2}$ & 0,75677 & 2 \\
$\mathrm{~A}_{3}$ & 0,75849 & 1 \\
$\mathrm{~A}_{4}$ & 0,75332 & 3 \\
$\mathrm{~A}_{5}$ & 0,63508 & 5 \\
\hline
\end{tabular}

The result of the calculation is shown in table 5 that $A_{3}>A_{2}>A_{4}>A_{1}>A_{5}$, it can be concluded that $\mathrm{A}_{3}$ Family Meatballs are business actors granted People's Business Credit, for the second alternative given KUR fund, $\mathrm{A}_{2}$, Krispy mushroom. In this election, decisionmakers can make 1 or more decisions in KUR grant. It could be taken three (3) the highest value for granted the loan People's Business Credit.

\section{Conclusion}

From the results of the discussion on the feasibility of giving KUR using PSI method, it can be concluded, that is:

1. Preference Selection Index method is an effective method for decision makers to make accurate results of calculations because based on statistical calculations. 
2. The PSI method can generate the weights (w) needed to calculate criteria that affect attributes, and it is very beneficial for decision makers in time savings to determine weight values.

3. The PSI method is particularly suitable for alternatives that have a high rating and when compared to other MCDM methods, the PSI method is a very easy to understand method.

\section{Reference}

[1] P. harliana and R. Rahim, "Comparative Analysis of Membership Function on Mamdani Fuzzy Inference System for Decision Making,” J. Phys. Conf. Ser., vol. 930, no. 1, p. 012029, Dec. 2017.

[2] D. Siregar, D. Arisandi, A. Usman, D. Irwan, and R. Rahim, "Research of Simple MultiAttribute Rating Technique for Decision Support," J. Phys. Conf. Ser., vol. 930, no. 1, p. 012015, Dec. 2017.

[3] J. Jasri, D. Siregar, and R. Rahim, "Decision Support System Best Employee Assessments with Technique for Order of Preference by Similarity to Ideal Solution," Int. J. Recent Trends Eng. Res., vol. 3, no. 3, pp. 6-17, Mar. 2017.

[4] N. Nurmalini and R. Rahim, "Study Approach of Simple Additive Weighting For Decision Support System," Int. J. Sci. Res. Sci. Technol., vol. 3, no. 3, pp. 541-544, 2017.

[5] S. Syamsudin and R. Rahim, "Study Approach Technique for Order of Preference by Similarity to Ideal Solution (TOPSIS)," Int. J. Recent Trends Eng. Res., vol. 3, no. 3, pp. 268-285, Apr. 2017.

[6] G. Ginting, Fadlina, Mesran, A. P. U. Siahaan, and R. Rahim, "Technical Approach of TOPSIS in Decision Making," Int. J. Recent Trends Eng. Res., vol. 3, no. 8, pp. 58-64, 2017.

[7] R. Rahim, Mesran, A. Putera, U. Siahaan, and S. Aryza, "Composite performance index for student admission," Int. J. Res. Sci. Eng., vol. 3, no. 3, pp. 68-74, 2017.

[8] Mesran, R. K. Hondro, M. Syahrizal, A. P. U. Siahaan, R. Rahim, and Suginam, "Student Admission Assessment using Multi-Objective Optimization on the Basis of Ratio Analysis (MOORA)," J. Online Jar. COT POLIPT, vol. 10, no. 7, pp. 1-6, 2017.

[9] M. Madić, J. Antucheviciene, M. Radovanović, and D. Petković, "Determination of laser cutting process conditions using the preference selection index method," Opt. Laser Technol., vol. 89, no. October 2016, pp. 214-220, 2017.

[10] Mesran, G. Ginting, Suginam, and R. Rahim, "Implementation of Elimination and Choice Expressing Reality ( ELECTRE ) Method in Selecting the Best Lecturer ( Case Study STMIK BUDI DARMA ),” Int. J. Eng. Res. Technol. (IJERT, vol. 6, no. 02, pp. 141-144, 2017.

[11] R. Attri and S. Grover, "Application of preference selection index method for decision making over the design stage of production system life cycle," J. King Saud Univ. - Eng. Sci., vol. 27, no. 2, pp. 207-216, 2015.

[12] H. Nurdiyanto and Heryanita Meilia, "SISTEM PENDUKUNG KEPUTUSAN PENENTUAN PRIORITAS PENGEMBANGAN INDUSTRI KECIL DAN MENENGAH DI LAMPUNG TENGAH MENGGUNAKAN ANALITICAL HIERARCHY PROCESS (AHP)," in Seminar Nasional Teknologi Informasi dan Multimedia 2016, 2016, no. February, pp. 1-7.

[13] R. Rahim, S. Nurarif, M. Ramadhan, S. Aisyah, and W. Purba, "Comparison Searching Process of Linear, Binary and Interpolation Algorithm,” J. Phys. Conf. Ser., vol. 930, no. 1, p. 012007, Dec. 2017.

[14] R. Khorshidi and A. Hassani, "Comparative analysis between TOPSIS and PSI methods of materials selection to achieve a desirable combination of strength and workability in $\mathrm{Al} / \mathrm{SiC}$ composite," Mater. Des., vol. 52, no. June, pp. 999-1010, 2013.

[15] Kusrini., Konsep dan aplikasi Sistem Pendukung Keputusan. Andi. Yogyakarta: Andi The publishing company, 2007.

[16] S. Kusumadewi, S. Hartati, A. Harjoko, and R. Wardoyo, Fuzzy Multi-Attribute Decision 
Making (Fuzzy MADM). Yogyakarta: Graha Ilmu, 2006.

[17] J. Papathanasiou, N. P. B, T. Bournaris, and B. Manos, "A Decision Support System for Multiple Criteria Alternative Ranking Using TOPSIS and VIKOR: A Case Study on Social Sustainability in Agriculture," ICDSST, vol. 2, pp. 3-15, 2016.

[18] K. Maniya and M.G.Bhatt, "A selection of material using a novel type decision-making method: Preference selection index method," Mater. Des., vol. 31, no. 4, pp. 1785-1789, 2010.

[19] Mesran, K. Tampubolon, R. D. Sianturi, F. T. Waruwu, and A. P. U. Siahaan, "Determination of Education Scholarship Recipients Using Preference Selection Index," Int. J. Sci. Res. Sci. Technol., vol. 3, no. 6, pp. 230-234, 2017. 